\title{
CRISTIANISMO EVANGÉLICO Y CAPITALISMO PERIFÉRICO EN EL CHILE CONTEMPORÁNEO: DEL ASCETISMO INTRAMUNDANO A LA TEOLOGÍA DE LA PROSPERIDAD*
}

\author{
EVANGELICALISM AND PERIPHERAL CAPITALISM IN \\ CONTEMPORARY CHILE: FROM INNER-WORLDLY \\ ASCETICISM TO THE PROSPERITY THEOLOGY
}

\section{DAVID OVIEDO SILVA**}

Resumen: El artículo presenta las posibilidades de extrapolación de la teoría de Max Weber acerca del vínculo entre protestantismo y capitalismo en el marco de las relaciones entre cristianismo evangélico chileno contemporáneo y capitalismo periférico. La literatura especializada ha abordado la temática de modo tangencial, ya que si bien se han insinuado algunos vínculos, existen pocos estudios sistemáticos que pongan a prueba la hipótesis weberiana en un contexto latinoamericano y chileno. El ensayo presenta las perspectivas de estudio más promisorias a la luz de las consideraciones teóricas y empíricas analizadas. Uno de los campos más sugerentes de investigación sociohistórica se operacionaliza en el nexo entre la teología de la prosperidad (una de las vertientes del neopentecostalismo) y neoliberalismo en el Chile Contemporáneo. Más allá de las evidentes diferencias histórico-teológicas entre calvinismo y neopentecostalismo, ambos fenómenos religiosos permiten una legitimación ideológico-cultural del capitalismo, en tanto modo de producción que requiere ser internalizado en el plano de las motivaciones de los sujetos. A partir de este tipo de investigaciones, es posible un esclarecimiento del vínculo entre interpretaciones idealistas (énfasis cultural) y materialistas (acento tecnoeconómico) sobre procesos de cambio histórico.

Palabras clave: Weber, cristianismo, capitalismo, teología de la prosperidad, Chile contemporáneo.

AвstRACT: This paper presents the possibilities of extrapolation regarding Max Weber's theory on the relationship between Protestantism and capitalism within the framework of relations between contemporary Chilean Evangelical Christianity and peripheral capitalism. The literature has approached the subject tangentially, since, although some links have been suggested, there are few systematic studies that test the Weberian hypothesis in a Latin American and Chilean context. The essay presents the most promising study perspectives in light of the theoretical and empirical considerations analyzed.

* El artículo surge del Proyecto Fondecyt de Iniciación Ética evangélica y mentalidad capitalista en el Chile contemporáneo. Tipos ideales y evolución histórica desde la crisis desarrollista hasta la profundización del neoliberalismo (1964-2006), №11190376. Investigador Responsable.

** Doctor en Artes y Humanidades. Académico de la Universidad de Concepción, Concepción, Chile. Correo electrónico: davidoviedo@udec.cl. Orcid: https://orcid.org/0000-0003-2253-206X 
One of the most suggestive socio-historical research fields is operationalized in the link between the prosperity theology (neo-Pentecostalism) and neoliberalism in Contemporary Chile. Beyond their evident historical-theological differences (Calvinism and Neo-Pentecostalism), both religious phenomena legitimize capitalism from a cultural ideological point of view, as a mode of production that requires being internalized at the subjects' motivation level. From this type of research, it is possible to clarify the link between idealistic (cultural emphasis) and materialistic (techno-economic emphasis) interpretations of historical change processes.

Keywords: Weber, Christianism, capitalism, prosperity theology, Contemporary Chile.

Recibido: 26.08.2020. Aceptado: 18.05.2021.

\section{INTRODUCCIÓN}

C L estudio se ubica en la frontera interdisciplinaria entre Historia y USociología. El carácter historiográfico viene dado por la dimensión evolutivo-temporal del fenómeno a indagar, el método de análisis de fuentes y relevancia de los contextos histórico-económicos. La investigación se inserta en una Historia de las Religiones que enfatiza la necesidad de trascender contextos en clave comparativa (Bermejo, 2012, pp. 259-282). Sin duda, el estudio también se enmarca en una Sociología Histórica de la Religión, en el contexto de una actualización y proyección del paradigma weberiano a la luz de nueva evidencia histórica (Gorski, 2011, pp. 291 316). Las tesis de Weber sobre la ética protestante y el espíritu del capitalismo se aplican a un contexto específico del surgimiento del capitalismo en la modernidad, sin embargo, sugieren un tipo de conexión (afinidad electiva) entre religión y economía que es interesante extrapolar para otras condiciones histórico-sociales. En el caso chileno es sugerente comparar dos modelos económico-sociales opuestos en su enfoque respecto al progreso, léase desarrollismo y neoliberalismo. El propósito medular de esta investigación consiste en explicar la evolución sociohistórica de una ética cristiano-evangélica en relación con las exigencias de una mentalidad capitalista en el Chile Contemporáneo, con especial énfasis en la influencia de la teología de la prosperidad en un escenario neoliberal. El estudio permite superar ciertas dicotomías o preconceptos que afectan la reflexión sobre el hecho religioso. Es el caso de la típica asociación que se establece entre religión y premodernidad, en circunstancias que es posible relacionar las consecuencias de una mentalidad religiosa con dinámicas de modernización que transforman la sociedad y la cultura. Las pretensiones comparativas en 
Historia no suponen la réplica del fenómeno originario en sus proyecciones en el tiempo. Se postula la extrapolación de una confluencia entre religión y economía que explica en clave funcionalista cómo un sistema económico se legitima con la expansión de una mentalidad religiosa trascendiendo la especificidad de cada contexto histórico-teológico, si bien es interesante indagar cómo se manifiesta en distintas expresiones temporales.

\section{LA TESIS WEBERIANA: SENTIDO HISTÓRICO E IMPLICANCIAS TEÓRICAS}

La tesis de la Ética Protestante y el Espíritu del Capitalismo instaura un plano de investigación sociohistórica en relación con el nexo entre religión y economía, y a sus posibilidades de interdependencia en tanto fenómenos culturales. Es una teoría capaz de armonizar interés científico (inquietudes comparativas) con apertura a la comprensión de la subjetividad histórica, entendida como autodescripción de los sujetos religiosos sobre la dimensión económica de la existencia.

Weber se pregunta por la especificidad de la religión occidental para explicar el apogeo instrumental de Occidente. La dimensión soteriológica del cristianismo desempeña un rol crucial para el sociólogo alemán, ya que genera un nivel de angustia que se acentúa en el calvinismo y no se aprecia en tradiciones orientales como el hinduismo o el confucionismo. Está en juego la salvación predestinada en el calvinismo por el designio divino como doctrina de la elección. La clave radica, entonces, en llevar una vida digna de la condición de redimidos por Dios, se realizan buenas obras porque se es salvo y no para ser salvo. La entrega ascética a la profesión emerge como autoconfirmación de haber recibido la gracia soberana. Se desarrollan posibilidades de acumulación financiera que surge de individuos productivos propensos al ahorro y alejados de una vida disipada. La premisa weberiana no corresponde al afán de lucro: un corsario o un encomendero de la Conquista pueden demostrar anhelo de riqueza fácil al margen de una metodología ascética de acceso. Una implicancia significativa es cómo se redefine una lógica de medios-fines: el trabajo pasa a conformar un ethos moral, un estilo de vida, trascendiendo el significado de medio de subsistencia.

El protestantismo ascético se define como condición necesaria, pero no suficiente para la expansión cultural del ethos capitalista. Como estudioso de la historia económica medieval, Weber es consciente del desarrollo anterior del capitalismo en relación con el calvinismo y con la Reforma. 
A posteriori, la mecánica de modernización capitalista no requiere del incentivo religioso para lograr adhesión, se autonomiza en la reproducción de un comportamiento económico correcto. Más allá de su interés por las religiones comparadas y el protestantismo, Weber es un teórico de la secularización, así como los clásicos de la sociología profesional. Parece inferirse una arista hegeliana en su raciocinio: en la historia apreciamos la incidencia de un ardid de la razón como efectos no deseados de procesos contrarios o distintos a las consecuencias que propician. La diferencia con Hegel radica en la culminación filosófico-histórica del fenómeno a través del despliegue dialéctico del Espíritu. En contraste, Weber explica la transferencia desde la religión a la materialidad ${ }^{1}$.

Es cuestionable la habitual atribución de determinista religioso que se suele hacer a Weber. Este lugar común proviene de una errónea lectura de La ética protestante y el espíritu del capitalismo. Jamás se plantea que el capitalismo haya surgido del protestantismo, antes bien, se señala la convergencia entre dos trayectorias históricas diferenciadas: calvinismo y mentalidad capitalista ${ }^{2}$. Weber designa esta confluencia como afinidad electiva. Se refiere a procesos acotados y no ingresa a la reflexión marxista acerca de un motor fundamental del desarrollo histórico. No opone un determinismo espiritual a uno materialista. Su hipótesis en La Ética Protestante y el Espíritu del Capitalismo escapa a este dilema, ya que no se sitúa en la tensión dialéctica entre infraestructura y superestructura (Weber, 2003, pp. 106-107). En lenguaje marxista, ambos fenómenos (ascetismo calvinista y psique capitalista) son superestructurales de índole cultural. Es cierto que la valoración de lo religioso suele reflejar posiciones acerca de la controversia materialismo v/s idealismo. Esto es manifiesto en el caso del marxismo, pero en sus estudios sobre religión Weber no plantea la inversión teóricocausal del paradigma marxista, sino que posiciona el problema en otro nivel: afinidades electivas, especificación del contenido de causalidades en el marco de singularidades históricas acotadas.

Luego, no es posible concluir que Weber sobredimensione el factor religioso ${ }^{3}$. A pesar de que admite asociación (no influencia causal) entre

\footnotetext{
${ }^{1}$ El contraste solo tiene sentido en el caso analizado por Weber, porque sabemos que el autor de $\mathrm{La}$ ética protestante no está inspirado por una motivación teleológica histórica.

${ }^{2}$ Tras un debate que ha durado más de 100 años, prevalece una visión que concede razón a Weber respecto al vínculo entre capitalismo y calvinismo, pero que extiende el análisis a otros factores no contemplados por el sociólogo alemán. Es el caso de los estudios de Gorski y su aporte sobre el rol de la burocracia de origen calvinista en la modernización capitalista de la Prusia absolutista en el s. XVII (Gorski, 2011, pp. 153-186).

${ }^{3}$ Las alusiones respecto al pensamiento de Max Weber se refieren a La Ética Protestante y el Espíritu del Capitalismo, ya sea sobre fragmentos concretos de la obra o a una interpretación general del texto.
} 
ascetismo calvinista y espíritu capitalista, es enfático en afirmar que la racionalización de la vida moderna termina por automatizar el capitalismo al punto que ya no requiere mística alguna para su expansión, atendiendo a la radical secularización de las sociedades que experimentaron la Reforma Protestante. El contenido fundamental de la tesis weberiana explica el surgimiento de la mentalidad capitalista en el mundo moderno, pero no profundiza en las condiciones para la preservación del capitalismo. ¿Cómo interpretar entonces sus declaraciones sobre el capitalismo contemporáneo? Básicamente, se trataría de un esfuerzo por demarcar con precisión el objeto de estudio, enfatizando que la base empírica de su teoría se apoya en los orígenes del sistema capitalista (Lenski, 1967). Por cierto, Max Weber no plantea la influencia de una teología en una mentalidad productiva o de consumo, sino que se trata de percepciones o inclinaciones psico-culturales, donde economía y religión confluyen en una suerte de química histórica (Rodríguez, 1995, pp. 45-67).

Se ha criticado su vocación por avanzar hacia dimensiones científicoexplicativas de la historia dado el afán por relacionar variables y explicar diferenciaciones en planos comparativos, no obstante el énfasis epistémico en una sociología de la comprensión situada en las antípodas de un reduccionismo nomotético. Weber representa un equilibrio difícil de reeditar entre aproximación científica y apertura a la subjetividad histórica ${ }^{4}$.

Weber apunta a un objetivo de comprensión historiográfica sin pretensiones de generalización causal, se trata de relacionar una disposición religiosa con una mentalidad económica inherente al ethos capitalista. No establece cuánto influye la variable calvinista, sino que busca especificar cómo incide, cómo la teología se traduce en un modus operandi en el plano de las motivaciones e interpretaciones de la acción económica. Podríamos

\footnotetext{
${ }^{4}$ A pesar de las críticas, el paradigma weberiano lleva un tiempo considerable de revalorización al alero de una tradición intelectual neoconservadora estadounidense, desde Daniel Bell (2004) hasta Samuel Huntington (2004). Una apreciación semejante cabe advertir en Peter Berger o en el marco de la revalorización del debate sobre el nexo entre cultura y desarrollo económico (Inglehart y Welzel, 2005). También hay una recuperación en Robert Bellah, no incompatible con matices críticos, ya que se inserta en la línea de erudición sociohistórica sobre la especificidad de la variable religiosa per se, si bien critica cierta autorreferencia protestante en su valoración del peso histórico-cultural del calvinismo. Desde ese discutible patrón de referencia, Weber interpreta otras tradiciones religiosas influyentes en la Historia (Bellah, 2017, p.730). Pero más allá de sus aprensiones las observaciones de Bellah se insertan en el universo teórico weberiano. Recientemente, se ha descubierto que diversos factores fueron decisivos en la modernización capitalista alemana: desarrollo político-institucional, cosmopolitismo urbano, expansión educacional e innovación técnica. Es una incidencia multidimensional verificada tanto en regiones protestantes como católicas (Cantoni, 2015). Pero esto no invalida la tesis weberiana, ya que no plantea una jerarquía de asignación causal, sino que una confluencia de mentalidades entre capitalismo y calvinismo.
} 
insertar a Weber en una historia de las mentalidades, integrando los aspectos psicológicos y teológicos en la conformación de una actitud hacia el trabajo y la generación de riqueza. Economía y religión se entrelazan en un marco histórico-religioso acotado, pero surge la expectativa de extrapolar el raciocinio a otros escenarios doctrinarios y temporales ${ }^{5}$.

\section{MODELOS DE DESARROLLO EN EL CHILE CONTEMPORÁNEO. CONSECUENCIAS SOCIO CULTURALES}

La cuestión de los modelos de Desarrollo no constituye el eje analítico de la presente investigación, sino que es el marco histórico-material desde donde se insertará un estudio de historia cultural, a semejanza del trabajo weberiano que asocia dos tipos de mentalidad (religiosa y económica).

Lo usual ha sido relacionar economía con religión, posicionándose al factor espiritual como efecto de dinámicas tecno-económicas desde una óptica influida por el materialismo histórico. Se asiste a la proletarización de la marginalidad, prolongándose la lógica de pauperización que se presentó en el mundo rural (Salazar, 1985). Esto genera bolsones de miseria urbana coincidentes con la modernización e industrialización. En este contexto, el modelo produce exclusión social en la medida que se desarrolla, por ende, se refuerzan los contextos sociohistóricos que el pentecostalismo requiere para su crecimiento. Tal es la interpretación sobre el refugio de las masas que desarrolla Lalive d'Epinay: en un contexto de desadaptación so-

\footnotetext{
${ }^{5}$ Reviste interés la posibilidad de interpretar con categorías weberianas el caso del Opus Dei, específicamente por la distinción doctrinaria del movimiento como afán de santificación por medio del trabajo. Sin embargo, surgen dos objeciones iniciales a la posibilidad de una extrapolación: los planteamientos de Escrivá de Balaguer no se relacionan directamente con temas soteriológicos, sino que se orientan a la expectativa de co-participar del trabajo creador de Dios. Otra diferencia importante se relacionaría con las consecuencias de movilidad social de ambos procesos. Parece relevante en el caso calvinista (comerciantes holandeses, escoceses y estadounidenses que acceden a posiciones de élite desde sectores medios) y algo por investigar en el derrotero socioeconómico de individuos pertenecientes al Opus Dei. No cabe descartar casos significativos de ascenso de capas medias, pero la duda surge sobre la movilidad desde estratos inferiores a propósito de algunas premisas del movimiento: la infelicidad se explica por la resistencia de las personas a la aceptación de su condición en la sociedad. Es una afirmación que podría reproducir ciertas características premodernas de una sociedad estamental en búsqueda de su estabilización (el obrero debe esmerarse en la obra bien hecha y no sufrir por su condición). El tema es sugerente por sus matices históricos, teológicos y sociológicos en relación al nexo entre religión y economía.
} 
cial, el inmigrante de campo-ciudad encontraba en el pastor y en la iglesia una reedición de la comunidad rural perdida (Lalive d’Epinay, 1968) 6 .

Bajo este contexto histórico, es posible inferir que las iglesias evangélicas potenciaran un ethos económico orientado a la subsistencia y autoayuda comunitaria para después propiciar valores de honestidad, laboriosidad y transparencia asociadas a las exigencias culturales del desarrollismo (Ossa, 1991) ${ }^{7}$. Esto habría posibilitado una disposición favorable hacia el trabajo y sus exigencias, aunque dentro las limitaciones estructurales de un capitalismo periférico y dependiente. El sistema económico-social establecido por la Dictadura de Pinochet cambia el escenario estructural recién descrito. Trasciende el carácter comunitario de la vivencia pentecostal, particularmente valorada en el contexto desarrollista, y supone un fuerte énfasis individual en temas teológicos decisivos como salvación, conversión, regeneración. Esta distinción evangélica es relevante para comprender la revitalización del ritmo de crecimiento evangélico durante los ochenta. Se habría verificado una revolución capitalista (Moulián, 1997), generándose una transformación sociocultural profunda a partir del accionar de un Estado neoliberal y autoritario ${ }^{8}$.

Emerge un enfoque individualista del ascenso socioeconómico y la gratificación material, esto es plenamente compatible con la individuación de la teología evangélica, caracterizada por una mentalidad que determina un antes y un después de la conversión personal. El modelo económico im-

\footnotetext{
${ }^{6}$ El presente estudio no pretende discutir este tipo de lógicas explicativas, ya que se busca complementar la realidad estructural del fenómeno con una interpretación sociocultural de los actores históricos que lo conforman, en relación con la manera en que configuran una eventual ética asociada a los requerimientos capitalistas.

${ }^{7}$ Podríamos extrapolar en este contexto las nociones thompsonianas de economía moral, no en el ámbito de movimientos antisistémicos, sino que en la propiciación de acciones económicas a partir de una ética subalterna desde la solidaridad a una meritocracia "bíblica" (Aguirre, 2010).

${ }^{8}$ Por cierto, al emplear el término "dictadura", me refiero al régimen establecido por Augusto Pinochet en el período 1973-1989. Conocido es su carácter pionero en el establecimiento del neoliberalismo (resistido por una derecha tradicional y nacionalista influyente en los primeros años de la Junta Militar) en un contexto global (posteriormente implementado por Thatcher en Reino Unido y por Reagan en Estados Unidos), así como el carácter traumático de su ejercicio del poder, promoviendo la despolitización de la sociedad a través de la brutalidad del exilio, la represión y las violaciones sistemáticas a los derechos humanos. Aun así, el régimen delineó su propia salida institucional; no obstante, la perspectiva histórica indica que se trataría de consideraciones formales de ejercicio del gobierno, manteniéndose intacto el diseño de sociedad y la distribución del poder económico y político. Las consecuencias de la dictadura no son de carácter coyuntural, sino que de mediana o larga duración, cuestión que recién comienza a revertirse con las recientes y masivas movilizaciones de 2019 y su demandas de un nuevo pacto social y constitucional que origine otro ciclo histórico en el país.
} 
plementado difiere sustantivamente del desarrollismo. Este dimensionaba la actividad industrial más allá de sus imperfecciones competitivas como sector productivo estratégico. Bajo este escenario, se incentiva el tipo ideal de un empresario que surge sobre la base del tesón y la laboriosidad. Con el advenimiento del neoliberalismo, se impone una construcción ideal-típica que no tiene que ver exclusivamente con el exportador disciplinado y esforzado, aunque algunos de estos elementos se verifiquen en un análisis de imaginarios sociales. Lo cierto es que se maximiza la importancia del capital frente al trabajo, en consonancia con la lógica especulativa inherente al movimiento financiero. De ahí es posible colegir que la propagación de la imagen del empresario o industrial laborioso afín a la descripción weberiana es desplazada por la representación del inversionista que implementa con eficiencia una fórmula de acumulación. En las categorías culturales propias de la revolución capitalista, las consideraciones ontológicas se subordinan al éxito instrumental, por ende, el consumo aparece como definición de la identidad, así como el ser equivale al tener.

\section{ÉTICA EVANGÉLICA Y NEOLIBERALISMO: DEL ASCETISMO A LA PROSPERIDAD ${ }^{9}$}

¿Qué consecuencias podría tener el proceso psicohistórico descrito en la constitución de una ética evangélica respecto al espíritu capitalista neoliberal que promueve la Dictadura? ${ }^{10}$. Cabe hipotetizar que se debilita la es-

\footnotetext{
${ }^{9}$ En el presente ensayo, se trata de ahondar en las implicancias actitudinales de índole económica, a partir de disposiciones inherentes a mentalidades religiosas. Otra forma interesante de vincular economía con religión consiste en la teoría de la rational choice, representada por Finke, Iannaccone o Stark (Frigerio, 2000). Se trata de entender las decisiones de adhesión religiosa, a partir de la premisa antropológica de búsqueda de privación mínima y satisfacción máxima. Es una perspectiva cuestionada por un posible sesgo de reduccionismo mercantil, sin embargo, posibilita comprender cómo se dinamizan las decisiones espirituales de las personas en un contexto sociohistórico signado por el pluralismo, antes que por el paradigma de la secularización. La teoría de la elección racional se distancia de Durkheim o Berger y su reminiscencia nostálgica de un dosel sagrado o estructura homogénea de plausibilidad en la sociedad occidental a propósito de la religión, cuestionando además el supuesto carácter monolítico de la primacía del cristianismo en el medioevo (más impregnado de pensamiento mágico que de una cosmovisión religiosa). A nivel contemporáneo, el fenómeno de la teología de la prosperidad admite ciertas opciones de comprensión desde la rational choice, ya que las necesidades que los sujetos buscan satisfacer en iglesias neopentecostales no son solo financieras, sino que apuntan a la seguridad psíquica o a una aspiración integral de bienestar.

${ }^{10} \mathrm{Si}$ bien hay excepciones dignas de estudio (Mansilla y Orellana, 2019), considero que permanece incólume la aseveración respecto a funcionalidad de las principales iglesias evangélicas chilenas como medio de legitimación política de la dictadura, en contraste con la postura predominantemente crítica
} 
tructura ética del pensamiento anterior, desplegado al alero de un desarrollismo que fomentaba la asociación entre esfuerzo productivo y adquisición de riqueza. La compulsiva modernización capitalista que experimenta el país con el régimen militar, especialmente a partir de los ochenta, se ejecuta bajo una atmósfera cultural de creciente hegemonía mediática con la expansión de la presencia de televisión en los hogares. Esto contribuye a forjar una sobrevaloración de la inmediatez y una despenalización psicosocial de tendencias hedonistas. La situación contemporánea chilena combina premodernidad material con ciertos rasgos de posmodernidad sociocultural (Hoppenyan, 1994) ${ }^{11}$. Es interesante investigar hasta qué punto la adhesión pentecostal a una ética económico-laboral resiste los embates de las tendencias socioculturales hegemónicas.

Asimismo, las últimas décadas contempladas en el estudio (desde los noventa hasta comienzos del siglo XXI) coinciden con la aparición de una nueva tendencia religiosa en el universo evangélico; la llamada teología de la prosperidad. Es una corriente religiosa donde se conceptualiza la fe como fuente de provisión de bendiciones materiales. Se implementa una lógica de pacto o devolución contractual donde el creyente es persuadido a invertir ofrendando su dinero a la iglesia con la convicción de obtener retribución futura ${ }^{12}$. Para que llegue la bendición de Dios se requiere dar un paso de fe siendo generoso en la ofrenda. El principio subyacente es que el sufrimiento obedece a un déficit de espiritualidad: "si una persona está permanentemente en enfermedad o pobreza, esto significa que a esta per-

y de defensa de los derechos humanos de la iglesia católica. Una red de 33 pastores evangélicos representativos de las congregaciones más importantes del país suscribe la siguiente declaración en 1974: "El pronunciamiento militar de las Fuerzas Armadas en el proceso histórico de nuestro país es la respuesta de Dios a las plegarias de todos los creyentes, quienes ven en el marxismo a las fuerzas satánicas de la oscuridad en su mayor expresión" (Declaración de la Iglesia Evangélica Chile, 1974. Cfr. Lagos, 1988, p.157). Las Fuerzas Armadas aparecen como instrumento divino de salvación. Consecuentemente, el mundo no representa por sí mismo la encarnación del mal; la lucha entre el bien y el mal se especifica en su expresión geopolítica e ideológica: el este socialista antagoniza con un occidente libre y de raíces cristianas en el contexto de la Guerra Fría. En 1975, se realiza el Primer Te Deum Evangélico en la recientemente inaugurada Catedral Evangélica de la Iglesia Metodista Pentecostal de Chile (Archivo Televisión Nacional de Chile, 1975). También cabe mencionar una masiva y continua propaganda ideológico-religiosa en la década de los ochenta a través de Televisión Nacional de Chile (canal estatal); todos los fines de semana se transmitían extensos programas evangélicos estadounidenses (Jimmy Swaggart, Club 700, etc.).

${ }^{11}$ A pesar del carácter periférico del neoliberalismo chileno también se infieren de su funcionamiento las contradicciones culturales del capitalismo. El éxito económico se disocia de un disciplinamiento ascético constituyendo una imagen de hedonismo y ocio (Bell, 2004). En este sentido la élite propicia un imaginario sociocultural donde resulta más relevante la configuración de un estilo de vida que denote solvencia y que permita una liberación posmaterialista (Inglehart, 1991, pp. 59-101).

${ }^{12}$ De modo análogo a la compraventa de acciones en el sistema financiero. 
sona le está faltando la verdad del Reino de Dios" (Robertson, Cfr. Brower, Gifford y Rose, 1996, p. 27).

El fenómeno es de origen estadounidense y se ha trasplantado con fuerza a Centroamérica, particularmente en países donde se instalaron regímenes contrainsurgentes en los ochenta (El Salvador o Guatemala). En todo caso, el carácter aspiracional de la sociedad chilena post- autoritaria permite colegir que existe una influencia de la perspectiva teológica de la prosperidad en el imaginario evangélico-pentecostal. Es posible que la orientación se evidencia de modo más sutil y no por ello menos influyente, posiblemente por razones idiosincráticas inherentes al celo evangelizador del pentecostalismo chileno. La teología de la prosperidad podría encuadrarse sociohistóricamente en un sector del neopentecostalismo del Chile actual.

Podríamos inferir que existe conexión entre la teología de la prosperidad y la tesis weberiana, en tanto se trata de dimensiones sociohistóricas de integración entre religión y economía, pero Weber describe una realidad diametralmente distinta en términos de la concepción teológica del ascetismo calvinista y del lugar asignado al éxito material en dicha cosmovisión. El comerciante puritano es llamado a desconfiar de las riquezas, entendiendo su potencialidad para alejarlo de lo que debiera ser el norte de su vida: proyectar la gloria de Dios. Por cierto, la principal tensión calvinista es soteriológica: se trata de obtener certeza de salvación y esta se logra con un estilo de vida que refleja ser apartado para Dios en medio del mundo, racionalizando una plena dedicación al oficio y a la profesión como una santidad hecha sistema. Desde este ángulo, la prosperidad material viene como consecuencia del distanciamiento del hedonismo y del ocio, no es un objetivo en sí mismo.

El esquema de la teología de la prosperidad se plantea en clave contraria a una lógica medios-fines. El instrumento (abundancia material) se transforma en objetivo, por lo que asistimos a un proceso de radical autosecularización del dominio teológico. La inmanencia y la inclinación intramundana se imponen frente a la eventual espiritualidad del movimiento. Por cierto, existe apelación a las Escrituras, al poder de Dios, y a ciertos mantras neopentecostales, como la sangre de Cristo, en un escenario de guerra espiritual. Sin embargo, se trata de una religión explícitamente subordinada al mundo y a sus exigencias de rendimiento. El proceso calvinista es inverso, ya que el desencantamiento de la realidad y la secularización son efectos de un imaginario originalmente religioso. Es comprensible, entonces, la orientación financiera de la teología de la prosperidad y productiva en el 
caso del ascetismo intramundano. El problema del vínculo entre religión y economía se plantea y resuelve de forma claramente diferenciada. Sacrificio laboral de acuerdo con la concepción bíblica del trabajo versus especulación monetaria, bajo la promesa de un pacto que exige crecientes demostraciones de fe (ofrendas y diezmos).

En toda América Latina, es popular el canal Enlace, con referentes habituales como los datos "apóstoles" predicadores Cash Luna o Guillermo Maldonado, en el marco de una creciente influencia económica y cultural (Calderón, 2017). La retórica es fácilmente reconocible en los códigos de la teología de la prosperidad: Dios quiere prosperarte y debes ponerlo a prueba para comprobar cómo abre los cielos de la sobreabundancia de bienes para ti. El movimiento apela a un cierto empirismo: corrobora tú mismo la capacidad del Señor para bendecirte aquí y ahora. O también se puede verificar la generosidad de la provisión divina al observar el testimonio de otro creyente prosperado. Por supuesto, si algo falla en la expectativa de éxito financiero y se sigue hundido en la pobreza, es porque ha faltado fe, pues se han escuchado las voces disuasivas del legalismo religioso (mensajes propios de iglesias protestantes históricas o de evangélicas críticas frente al evangelio de la prosperidad) o de los enemigos de Dios en el mundo secular.

Es importante mantener frente al fenómeno una disposición de comprensión científico-social, al margen de la demonización teológica o de un reduccionismo racionalista. En términos estructural, funcionalistas, si una agencia social resulta reconocible, es porque desempeña un rol sistémico a pesquisar. A nivel internacional, han surgido reflexiones que expanden su horizonte teológico y existencial. Cabe puntualizar que no se trata solo de la búsqueda de mejoría material.

La premisa es la aspiración a un bienestar integral que incorpore la salud, el equilibro psicológico y la máxima felicidad posible. Más allá de los juicios peyorativos, se trataría de una teología de la abundancia (Félix-Jäger, 2019, pp. 279-290) en medio de las carencias materiales y de coberturas de prestación social en sociedades tercermundistas.

Peter Berger aborda la problemática en su ensayo Max Weber está vivo, bien y viviendo en Guatemala (Berger, 2010, pp. 3-10). Con la expansión del cristianismo evangélico en Centroamérica, se asiste a un cambio cultural que permitirá una mejor internalización de los valores del liberalismo económico. La hipótesis tiene algún nivel de asidero, pero supone una teleología discutible: una linealidad universalista en la progresión del capitalismo y el desarrollo. De este modo, la tesis weberiana surge como la contraparte sociocultural de los lineamientos de Rostow (Slater, 1999, pp. 114-121). 
También se ha objetado esta mirada por la subestimación de la singularidad doctrinaria del fenómeno evangélico en América Latina.

En el caso del Chile contemporáneo, es posible esquematizar las relaciones que apreciamos entre modalidades de expresión evangélica y modelos de desarrollo:
Pentecostalismo
Desarrollismo
Neopentecostalismo Neoliberalismo $^{13}$

Si comprendemos a Weber desde los contenidos vertidos en La Ética Protestante, parece más aplicable al nexo entre pentecostalismo y desarrollismo. Al entender la obra en un sentido más abstracto, como integración funcional entre economía y religión, se observa la legitimación de la economía a través de la religión. En términos equivalentes, la teología de la prosperidad constituye un caso de subjetivación neoliberal, ya que se intensifica el dominio instrumental y productivo en el plano de las motivaciones. Frente a la objeción de la discutible representatividad eclesiástica de la teología de la prosperidad en Chile, cabe replicar con la extensa cobertura de cadenas de televisión como Enlace en el país. Los telepredicadores representativos del evangelio de la prosperidad han visitado iglesias chilenas de carácter masivo, lo que revela un sello doctrinario en las llamadas "nuevas iglesias evangélicas" (especialmente en los llamados "ministerios"). Sostenemos que incluso en un contexto de pentecostalismo clásico (iglesia metodista pentecostal) apreciamos el influjo de esta corriente espiritual. Para corroborarlo, basta con recordar algunos episodios de impacto periodístico como los escándalos financieros de la alta jerarquía de la institución. Si bien la polémica ha girado en torno a la figura del Obispo Durán (Vega y Ramírez, 2018), se puede inferir tolerancia de la cúpula organizacional

\footnotetext{
${ }^{13}$ El sentido de esta distinción de asociaciones entre religión y economía no debe leerse en clave determinis, ya que las organizaciones y los individuos muestran capacidad de adaptación frente a los cambios en las exigencias económico-culturales. Es el caso del pentecostalismo clásico con la desinhibición de unos de sus líderes más reconocidos (Obispo Durán) al momento de enumerar sus bienes y describir su estilo de vida lujosa. Pero lo cierto es que en dicho ejemplo se revela la influencia de la ideología neopentecostal en las orientaciones de sentido del pentecostalismo clásico. Las diferenciaciones entre categorías histórico-teológicas (pentecostalismo y neopentecostalismo en su entrecruzamiento sociohistórico con el desarrollismo y el neoliberalismo) obedecen a la metodología weberiana de conformación de tipos ideales, entendiendo que es impensable que se verifiquen en términos exactos y nítidos en la realidad histórica. Los tipos ideales son puntos de partida y no de llegada en el proceso de investigación y se proyectan a la elaboración de hipótesis sociológicas para ser evaluadas en la complejidad del devenir histórico (Giddens, 1998, pp. 225-242). Bajo esta premisa metodológica, tiene sentido diferenciar un pentecostalismo ascético desarrollista frente a la despenalización neopentecostal del hedonismo y el éxito financiero en un contexto neoliberal (como indicio de aprobación divina).
} 
frente a un estilo de vida que despenaliza la prosperidad y el lujo. Esto no solo desafía el tradicional pudor evangélico en la materia, sino que va en línea con un creciente exhibicionismo de la élite chilena en tiempos de globalización neoliberal, a diferencia de la sanción social de antaño frente a un esnobismo exacerbado.

No postulamos reducir la religión a superestructura ideológica en clave marxista, sino que especificar cómo arraiga un modo de concebir la riqueza y el trabajo a partir de una cosmovisión religiosa. La sociedad chilena contemporánea atraviesa procesos relevantes de secularización y pluralismo, pero aún no hay elementos de juicio empírico para aseverar su carácter poscristiano. Ya advertía Durkheim acerca de la dificultad de encontrar un equivalente funcional a la religión como estructura de integración normativa (Durkheim, 2012). El sujeto llega a un grado inédito de autocontrol del comportamiento a través de la prescripción religiosa, entendiendo los alcances de la omnisciencia divina y el respaldo sagrado de sus reglas de conducta y orientaciones de sentido. En una lectura funcionalista, el fenómeno de estabilización sistémica vía aceptación de valores es equivalente, más allá de la apelación a las emociones por parte de la teología de la prosperidad, a la inversa de la jaula de hierro descrita por Weber. Pero en ambos casos se propicia una racionalización de la fe en tanto el espíritu deviene en lógica instrumental.

Cuando sostenemos la eficacia de la legitimación religiosa de una mentalidad económica, no restringimos la religión a epifenómeno de una dinámica material, sino que precisamos su carácter imprescindible para configurar este tipo de internalización sistémica.

Siguiendo a Philip Gorski, sociólogo de la historia de la Universidad de Yale, se está en condiciones de problematizar el axioma que establece la siguiente relación: a mayor diferenciación, mayor secularización (Gorski y Altinordu, 2008, pp. 55-85). Esto se verifica a partir de nuestra extrapolación weberiana, ya que tanto en el caso calvinista como en la teología de la prosperidad se agudiza el poderío de la religión como mecanismo de control de la conducta y el sentido. Para acceder a esta profundidad de dominio, la religión no necesita continuar atada al poder político y coercitivo, más bien requiere su automatización para influir de forma más decisiva en las orientaciones biográficas del creyente. En categorías luhmannianas, la religión se libera de condicionamientos sistémicos anteriores a la diferenciación funcional (Luhmann, 2007) y, de ese modo, se puede distinguir del entorno en su perfilamiento más auténtico (código inmanencia-trascendencia), respondiendo así a las necesidades existenciales que explican su vigencia histórica. 
Considerando el marco contemporáneo de esta tentativa de extrapolación (neopentecostalismo), encontramos tanto su visibilización teológica en la doctrina de la prosperidad como su faceta empírica sociológica: iglesias como las comunidades cristianas en el Chile actual (surgidas en los años setenta) de matriz carismática, pero que no fomentan explícitamente una despenalización del afán de lucro.

Después de 1980, comienza a advertirse tendencias inéditas en el mundo evangélico, ya que emergen grupos que carecen de una identidad denominacional clara. Por sobre las expresiones carismáticas, proporcionan vínculos comunitarios para sujetos sumidos en la vorágine de modernización que se desata especialmente en la segunda mitad de los ochenta. Prefieren llamarse solamente cristianos despreciando designaciones institucionales. Manifiestan en su doctrina y liturgia ciertas semejanzas con el histórico movimiento pentecostal chileno ${ }^{14}$, pero se desarrollan en un contexto socioeducativo algo lejano a la marginalidad evangélica. Todos estos rasgos diferenciadores caracterizan al neopentecostalismo chileno a nivel sociológico, y en algunos casos presentan influencias histórico-doctrinarias afines a la teología de la prosperidad (Fediakova, 2004, pp.253-284). ¿Cómo relacionar las tesis neopentecostales con los clásicos planteamientos weberianos sobre puritanismo calvinista y ascenso de la modernidad? El caso arquetípico descrito por Weber implicó tal nivel de racionalización teológica que terminó por disgregar el contenido místico del cristianismo

\footnotetext{
${ }^{14}$ Incluso a nivel interpretativo se aprecia cierta proyección teórica de las tesis de Lalive d’Epinay. El sociólogo y teólogo suizo realiza un célebre estudio en terreno en el Chile de la década de los sesenta, sosteniendo su legendaria teoría durkheimniana marxista para explicar la expansión del pentecostalismo en Chile en el contexto histórico-económico del desarrollismo y la hipertrofia urbana. El elemento durkheimniano aparece cuando Lalive introduce el factor anómico al analizar las consecuencias psíquico-sociales de una realidad material. Las iglesias pentecostales ofrecen el ambiente de estabilidad y significado inteligible que el migrante campo-ciudad requiere para soportar la exclusión (Lalive d'Epinay, 1968a). En términos generales y funcionales, Lalive sustituye el patrón de hacienda por el pastor pentecostal, explicando la equivalencia de relaciones de seguridad y sumisión que experimenta el feligrés evangélico; no obstante, existen matices relevantes como la intensidad de la experiencia espiritual en un contexto de apertura emotiva (Lalive d'Epinay, 1968b). Las conclusiones de Lalive siguen siendo objeto de valoración y debate contemporáneo (Wynarczyk, 2009). Sostengo que en la actualidad no se requiere el desarraigo migratorio para la producción de anomia, basta con las implicancias existenciales de una exposición compulsiva y alienante a la globalización y la tecnificación de las relaciones humanas. Es un planteamiento clásico que redefine su sentido, pero mantiene posibilidades de interpretación, reemplazando migración por globalización neoliberal y pentecostalismo clásico por neopentecostalismo y teología de la prosperidad (Oviedo, 2006, pp. 21-33). En el mismo sentido, cabe tener presente la patologización culposa de la realidad económico-cultural contemporánea y la inversión alienante de los que consideramos desarrollo personal: la autoexplotación se confunde con realización (Chul Han, 2017). Surgen condiciones favorables para un encauzamiento religioso de estas tendencias autodestructivas en contextos resistentes a la secularización (pluralismo religioso latinoamericano y chileno).
} 
(desencantamiento del mundo); por consiguiente, se configuró un escenario histórico-sociológico especialmente propiciador de la modernización sociocultural. Por su parte, el esquema doctrinario neopentecostal genera ámbitos de reflexión en áreas no estrictamente teológicas de desarrollo; la vivencia religiosa se torna eminentemente mística y carismática. Es una propuesta espiritual que puede servir de adiestramiento terapéutico para los individuos frente a los avatares de la modernidad tardía, pero el desenlace de la dinámica se diferencia de la racionalización del cristianismo que determinó el calvinismo reformado.

El fenómeno se puede interpretar en clave sociológica posfundacional y líquida (Bauman, 2003), donde las iglesias neopentecostales disuelven la noción de comunidad para fomentar un individualismo instrumental que permite una mejor adaptación del sujeto a las exigencias productivas y a los estándares de consumo (Mansilla, Leiva y Muñoz, 2017, pp. 172-185) ${ }^{15}$.

Predomina una dimensión terapéutico-existencial en su experiencia cristiana, favoreciendo una inserción estratégica de profesionales destacados en ámbitos de decisión ${ }^{16}$. La expectativa es que políticos y empresarios cristianos promoverán el Reino de Dios en la sociedad. No obstante, emerge una retórica anticapitalista en algunos documentos de las comunidades cristianas, pero su estrategia de cristianización de la sociedad no fomenta cuestionamientos sistémicos al estilo de la teología de la liberación.

De esta manera, el neopentecostalismo sociológico también favorece un proceso de subjetivización neoliberal, si bien manifiesta mayor afinidad doctrinaria con los presupuestos calvinistas acerca de la laboriosidad y el rigor. En último término, el neopentecostalismo chileno contemporáneo también considera el éxito económico-social como bendición y de esa forma el reino de Dios se presenta más atractivo a los no creyentes.

En suma, es sugerente pesquisar la influencia de contenidos de la teología de la prosperidad en la evolución (o debilitamiento) de una ética evangélica frente al capitalismo posfordista periférico materializado en Chile

\footnotetext{
${ }^{15}$ Proyectando hacia hoy, podríamos afirmar que la preservación de un sentido comunitario de la religión implica la vigencia de una noción de sujeto no reducido a criterios de desempeño, que es precisamente lo que se tensiona en un marco dataísta de poshmanismo (Harari, 2016, p. 426). Bajo ese escenario, es más probable que el lenguaje religioso diluya su diferenciación respecto a los códigos de sistema económico (teología de la prosperidad) y por ende es una retórica que contamina la trascendencia con reiteradas apelaciones a la inmanencia (Luhmann, 2007).

${ }^{16}$ Podríamos afirmar que tanto el neopentecostalismo como la teología de la prosperidad responden a una dinámica post-secular (Habermas, 2008, pp. 3-20; Garzón, 2014, pp. 101-112), en tanto combinan orientaciones de la tradición (rasgos pentecostales) con prescripciones modernas (ascenso profesional, éxito económico) en su ethos sociorreligioso.
} 
desde los noventa hasta la actualidad. Si bien las premisas de Weber constituyen la motivación teórica principal de esta reflexión sociohistórica, cabe suponer cierta permeabilidad del pensamiento religioso-evangélico frente a los cambios socioeconómicos que se experimentan en el Chile contemporáneo ${ }^{17}$, esto explica la eventual conexión entre desarrollismo y ascetismo, así como el hipotético nexo entre neoliberalismo y teología de la prosperi$\operatorname{dad}^{18}$.

\section{CONCLUSIÓN}

A modo de conclusión teórica y posibilidad hipotética para futuros estudios empíricos, cabe afirmar que no obstante la profunda disparidad teológica y sociohistórica de los casos calvinista y evangélico contemporáneo, observamos una funcionalidad análoga de la religión como dispositivo de legitimación e internalización cultural del sistema económico.

Esto no supone que la religión se reduzca a su dimensión material, sino que presenta esta faceta en su desenvolvimiento en el mundo, siendo posible visualizar la interacción entre religión y economía en la sociedad contemporánea. Tampoco postulamos que las causas centrales de los fenómenos históricos sean de carácter tecnoeconómico. Aun así, Weber no se perfila como contrario al marxismo, sino que va más allá del materialismo histórico al profundizar en la imbricación entre las fuerzas productivas y los factores culturales que constituyen procesos de cambio social. Al fin y al cabo, este tipo de aproximaciones al fenómeno religioso permite ahondar en dinámicas de secularización e incluso de post-secularidad en el Chile actual.

${ }^{17}$ Berger (1995, pp. 5-18) aclara el vínculo entre religión y globalización económico-cultural bajo las premisas empíricas del pluralismo. Es el tránsito del destino a la elección en las exploraciones espirituales de los sujetos.

${ }^{18}$ Este ensayo no se compromete empíricamente con el eventual impacto favorecedor de la expansión pentecostal y neopentecostal en procesos objetivos de desarrollo económico, sino que se plantea la internalización de una actitud hacia el rendimiento productivo o financiero que resulta compatible con el desarrollismo y el neoliberalismo, a partir de los énfasis teológicos correspondientes del pentecostalismo y el neopentecostalismo. Esto resulta de la inspiración weberiana del estudio, que no consiste en una relación de causalidad inversa al marxismo, sino que en la confluencia actitudinal entre una mentalidad religiosa y una económica. Podría esgrimirse que sí se resalta la dimensión cultural del Desarrollo, pero esto es distinto a un compromiso empírico con la centralidad de la cultura en indicios mensurables de progreso (incrementos del PIB per cápita o del Índice de Desarrollo Humano, en la medida en que hay más adherentes a una religión determinada). El desarrollo es un fenómeno multidimensional en el que las consideraciones culturales interactúan con factores materiales como la estructura socioeconómica o el posicionamiento de una sociedad en la correlación de fuerzas de la economía internacional, lo contrario sería un planteamiento de determinismo cultural ajeno a la temática del estudio. 


\section{REFERENCIAS}

Aguirre, C. (2010). Economía moral de la multitud. Universidad Nacional Autónoma de México. http://conceptos.sociales.unam.mx/conceptos_ final/424trabajo.pdf

Archivo Televisión Nacional de Chile (1975). Primer Te Deum Evangélico. Servicio de Acción de Gracias. Disponible en https://www.youtube.com/ watch? $v=$ NIEabt1caRc\&feature $=$ emb_title

Bauman, Z. (2003). Modernidad líquida. Ciudad de México: Fondo de Cultura Económica.

Bell, D. (2004). Las contradicciones culturales del capitalismo. Madrid: Alianza.

Bellah, R. (2017). La religión en la evolución humana. Del paleolítico a la era axial. Madrid: Centro de Investigaciones Sociológicas.

Berger, P. (1995). Pluralismo global y religión. Estudios Públicos, 98, 5-18.

Berger, P. (2010). Max Weber is alive and well, and living in Guatemala: the protestant ethic today. The Review of Faith \& International Affairs 8(4), 3-9. Doi: https://doi.org/10.1080/15570274.2010.528964.

Bermejo, J. (2012). El método comparativo y el estudio de la religión. En F. Diez de Verdasco y F. García (eds.). El estudio de la religión (pp. 259-282). Madrid: Trotta.

Brower, S., Gifford, P., Rose, S. (1996). Exporting The American Gospel: Global Christian Fundamentalism. New York: Routledge.

Calderón, J. (8 de noviembre de 2017). Iglesias evangélicas y el poder conservador en Latinoamérica. Celag.org. Disponible en https://www.telesurtv. net/opinion/Iglesias-evangelicas-y-el-poder-conservador-en-Latinoamerica-20171108-0088.html

Cantoni, D. (2015). The Economic Effects of the Protestant Reformation: Testing the Weber Hypothesis in the German Lands. Journal of the European Economic Association 13(4), 561-598.

Chul Han, B. (2017). La sociedad del cansancio. Barcelona: Herder.

Durkheim, E. (2012). Las Formas Elementales de la Vida Religiosa. Ciudad de México: Fondo de Cultura Económica.

Fediakova, E. (2004). “Somos parte de esta sociedad”. Evangélicos y política en el Chile postautoritario. Política, 43, 253-284.

Félix-Jäger, S. (2019). Material Visions of the Good Life: Pentecostalism, Visual Culture, and the Prosperity Gospel. Pneuma, 41, 279-290. Doi: https://doi. org/10.1163/15700747-04102002.

Frigerio, A. (2000). Teorías económicas aplicadas a la religión: hacia un nuevo paradigma. Lecturas sociales y económicas, 34, 34-50.

Garzón, I. (2014). Postsecularidad: ¿un nuevo paradigma de las ciencias sociales? Revista de Estudios Sociales, 50, 101-112. Disponible en https://revistas. uniandes.edu.co/doi/pdf/10.7440/res50.2014.11.

Giddens, A. (1998). Capitalismo y la moderna teoría social. Un análisis de los escritos de Marx, Durkheim y Weber. Barcelona: Idea Universitaria. 
Gorski, P. y Altinordu, A. (2008). After Secularization? Annual Review of Sociology, 34, 55-85.

Gorski, P. (2011). The protestant ethic revisted. Philadelphia: Temple University Press.

Habermas, J. (2008). El resurgimiento de la religión, ¿un reto para la autocomprensión de la modernidad? Diánoia, 60, 3-20. Doi: https://doi. org/10.21898/dia.v53i60.284.

Harari, Y. (2016). Homo Deus Breve historia del mañana. Barcelona: Debate.

Hoppenyan, M. (1994). Ni apocalípticos ni integrados: aventuras de la modernidad en América Latina. Ciudad de México: Fondo de Cultura Económica.

Huntington, S. (2004). Who Are We? The Challenges to America's National Identity. New York: Simon \& Schuster.

Inglehart, R. (1991). El cambio cultural en las sociedades avanzadas. Madrid: Siglo XXI.

Inglehart, R. \& Welzel, C. (2005). Modernization, Cultural Change, and Democracy. The Human Development Sequence. Nueva York: Cambridge University Press.

Lagos, H. (1988). Crisis de la esperanza. Religión y autoritarismo en Chile. Santiago: Lar.

Lalive d'Epinay, C. (1968a). El refugio de las masas. Estudio sociológico del protestantismo chileno. Santiago: Editorial del Pacífico.

Lalive d'Epinay, C. (1968b). La conquista pentecostal en Chile. Elementos para su mejor comprensión. Mensaje 17(170), 2-8.

Lenski, G. (1967). El factor religioso. Una encuesta sociológica. Barcelona: Labor.

Luhmann, N. (2007). La religión de la sociedad. Madrid: Trotta.

Mansilla, M., Leiva, S., Muñoz, W. (2017). Pospentecostalismo: del fundacionalismo al postfundacionalismo pentecostal chileno. Cinta de Moebio [online], 59, 172-185. ISSN 0717-554X. http://dx.doi.org/10.4067/S0717$554 X 2017000200172$.

Mansilla, M y Orellana, L. (2019). Evangélicos y política en Chile, 1960-1990. Política, apoliticismo y antipolítica. Santiago: Ril.

Moulián, T. (1997). Chile actual: Anatomía de un mito. Santiago: Lom / Arcis.

Ossa, M. (1991). Lo propio y lo ajeno. Identidad pentecostal y trabajo. Santiago: Rehue.

Oviedo, D. (2006). Modernidad y tradición en el pentecostalismo latinoamericano. Alcances socio-políticos en el Chile actual. Historia Actual On Line, 11, 21-33. Recuperado de https://historiaactual.org/Publicaciones/index. $\mathrm{php} / \mathrm{hao} / \mathrm{article} / \mathrm{view} / 165$.

Rodríguez, J. (1995). Las categorías de lo histórico en la sociología de Max Weber. Política y Sociedad, 18, 45-67.

Salazar, G. (1985). Labradores, peones y proletarios. Formación y crisis de la sociedad popular chilena del siglo XIX. Santiago: Ediciones Sur.

Slater, F. (1999). Las etapas del crecimiento económico de Rostow. Consideraciones sobre el evolucionismo como modelo interpretativo. Soñando 
el Sur, 2, 114-121. Disponible en http://repositoriodigital.uct.cl/handle/10925/302.

Vega, F. y Ramírez, P. (13 de diciembre de 2018). Tenso Te Deum evangélico: pugna valórica con el gobierno y alerta por lavado de activos del Obispo Durán. CIPER. Disponible en https://ciperchile.cl/2018/09/13/tenso-tedeum-evangelico-pugna-valorica-con-el-gobierno-y-alerta-por-lavadode-activos-del-obispo-duran/.

Weber, M. (2003). La ética protestante y el espíritu del capitalismo. Madrid: Alianza.

Wynarczyk, H. (2009). Chile, cien años de pentecostalismo y "el refugio de las masas". Buenos Aires: ECUPRES. 